
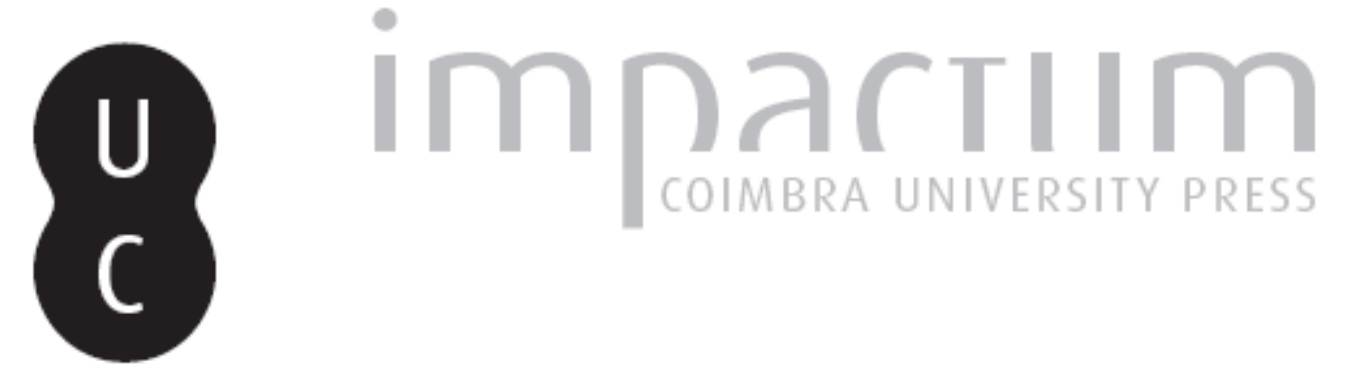

A necessária fricção (ou talvez não) = [Recensão a] Marsha Kinder e Tara McPherson (Eds.), Transmedia Frictions: The Digital, the Arts, and the Humanities

\author{
Autor(es): $\quad$ Fontes, Bruno
}

Publicado por: Centro de Literatura Portuguesa; Imprensa da Universidade de Coimbra

URL

persistente:

URI:http://hdl.handle.net/10316.2/39112

DOI:

DOI:http://dx.doi.org/10.14195/2182-8830_4-2_18

Accessed : $\quad$ 26-Apr-2023 16:23:31

A navegação consulta e descarregamento dos títulos inseridos nas Bibliotecas Digitais UC Digitalis, UC Pombalina e UC Impactum, pressupõem a aceitação plena e sem reservas dos Termos e Condições de Uso destas Bibliotecas Digitais, disponíveis em https://digitalis.uc.pt/pt-pt/termos.

Conforme exposto nos referidos Termos e Condições de Uso, o descarregamento de títulos de acesso restrito requer uma licença válida de autorização devendo o utilizador aceder ao(s) documento(s) a partir de um endereço de IP da instituição detentora da supramencionada licença.

Ao utilizador é apenas permitido o descarregamento para uso pessoal, pelo que o emprego do(s) título(s) descarregado(s) para outro fim, designadamente comercial, carece de autorização do respetivo autor ou editor da obra.

Na medida em que todas as obras da UC Digitalis se encontram protegidas pelo Código do Direito de Autor e Direitos Conexos e demais legislação aplicável, toda a cópia, parcial ou total, deste documento, nos casos em que é legalmente admitida, deverá conter ou fazer-se acompanhar por este aviso.

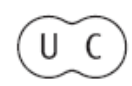



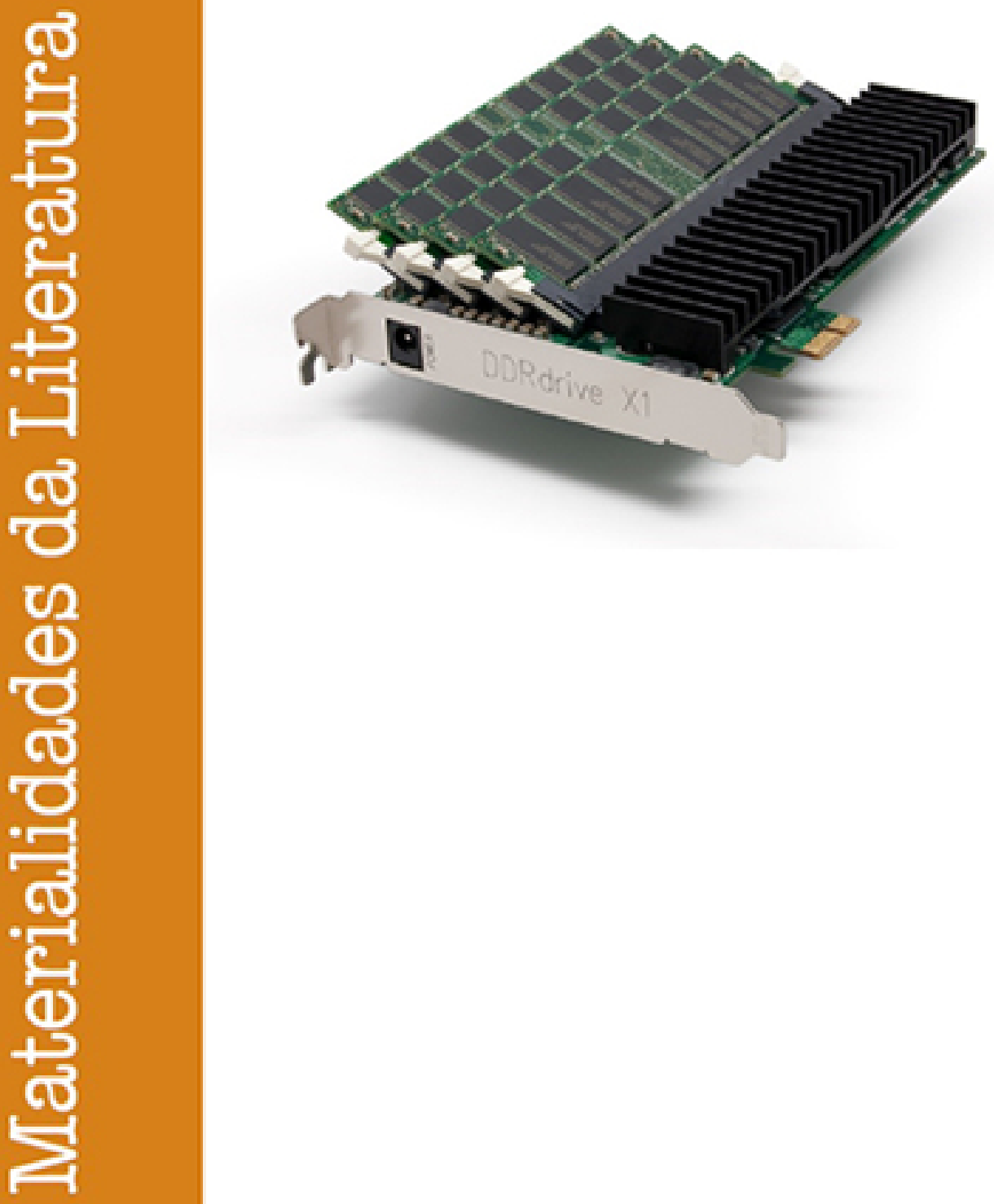

Vol. 4.2 (2016) ISSN 2182-8830

'Estudos Literários Digitais 2'

Manuel Portela e António Rito Silva (orgs.) 


\title{
A Necessária Fricção (ou talvez não) BRUNO FONTES
}

\author{
CLP | Universidade de Coimbra
}

Bolseiro da FCT

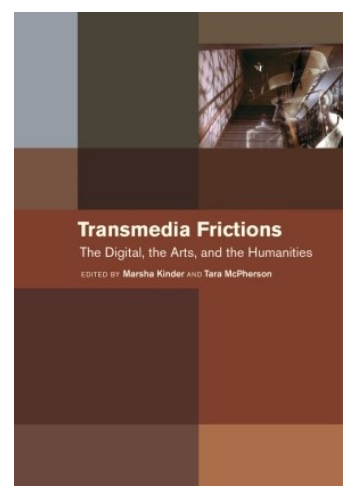

Marsha Kinder e Tara McPherson (Eds.), Transmedia Frictions: The Digital, the Arts, and the Humanities. Oakland, CA: University of California Press, 2014, 416 pp. ISBN 978-0-520-28185-1

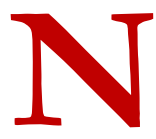
um panorama em que a confluência dos estudos literários com os dos media deixou já de ser uma novidade, e em que a discussão sobre a especificidade dos novos meios atingiu um certo desgaste, a recolha de ensaios Transmedia Frictions: The Digital, the Arts, and the Humanities consegue fazer-se notada por adicionar a estes debates um conjunto de variáveis incomuns: as questões políticas, sociais e de identidade que podem ser suscitadas pela ecologia digital.

Informa o prefácio que este livro aparece no seguimento do colóquio "Performing Interactive Frictions", realizado na University of Southern California em junho de 1999. Focando-se na relação entre a teoria e a prática nos campos das humanidades digitais e dos novos media e nas questões políticas e ideológicas que lhes são transversais, o certame procurou estabelecer uma linguagem partilhada entre as diferentes áreas que compartilham um interesse pela transmedialidade. Em todo o caso, Transmedia Frictions não se limita a um registo documental do mesmo: além de incluir contribuições que não marcaram presença no colóquio, criou também a ocasião para serem acrescentadas, nos casos em que os autores acharam necessário (tendo em conta os avanços tecnológicos e teóricos ocorridos desde 1999), notas adicionais aos trabalhos apresentados no evento. Este contexto impôs ainda a substituição do termo "interativo" por "transmedia", que está mais em consonância com a atualida- 
de e com a intenção (bem vincada) de examinar questões atinentes aos estudos fílmicos, narrativos, visuais e artísticos.

O volume está dividido em duas partes (antecedidas por introduções da responsabilidade das organizadoras), sendo que a primeira, intitulada "Medium specificity and productive precursors", contém oito textos com o foco na especificidade dos media digitais e na forma como as modalidades transmedia se relacionam com a continuidade entre os media tradicionais e os novos media. É evidente, na sua ordenação, uma lógica interna que os divide em quatro pares distintos: o primeiro redefine a especificidade dos media digitais através de uma decomposição analítica dos seus elementos; o segundo aborda os precursores analógicos das narrativas interativas; o seguinte aborda a relação entre a tecnologia digital e as bases de dados; e o último a forma como as modalidades fílmicas híbridas permitem uma experiência de interatividade. A parte II, "Digital possibilities and the reimagining of politics, place and the self', apresenta, por sua vez, os contextos culturais, sociais e políticos produzidos pela ecologia digital, contendo nove ensaios onde também se pode observar uma lógica distributiva: o primeiro trio aborda a forma como a utilização da tecnologia digital se relaciona com as noções mais tradicionais de "democracia"; o seguinte analisa as políticas do digital nas zonas de contacto entre os territórios físicos e os virtuais, e o último foca o corpo e a identidade, averiguando as correspondências entre a tecnologia e o tema da diferença.

O vasto número de temáticas convocadas e a sua complexidade é, como avisa ainda o prefácio, um "risco calculado" para estimular entre elas dialéticas - ou fricções - que as organizadoras consideram construtivas. Segundo as leis da física, uma "fricção" é uma força que atua quando dois ou mais corpos entram em contacto e há tendência ao movimento, e esta é uma metáfora bastante adequada para ilustrar a lógica que subjaz a esta escolha de temas e ao critério na já referida estruturação dos textos. Tal fica comprovado, desde logo, na fricção estabelecida entre o primeiro par de ensaios da parte I, "Print is flat, code is deep: The importance of media-specific analysis", de $\mathrm{N}$. Katherine Hayles, e "Postmedia aesthetics", de Lev Manovich, e na forma como a mesma se reverbera ao longo dos seguintes.

Reconhecendo que "[1]iterary criticism and theory are shot through with (...) assumptions specific to print” (20), Hayles propõe uma comparação entre o hipertexto em forma impressa e o que é instanciado num computador (por meio de uma tipologia que os considera de formas distintas), catalogando os movimentos entre estes media como um processo histórico que veio alterar a materialidade dos textos literários. Mas, evitando maniqueísmos e sintonizando-se com os estudos literários tradicionais, considera o livro uma forma demasiada "robusta" para cair na obsolescência face ao meio digital. Já Manovich discute a evolução que conduziu ao atual contexto de convergência de meios, concluindo que se o digital incorporou todos os media precedentes já não faz sentido pensar em termos de uma especificidade; mas dado que 
"no new topology (...) came to replace media-base typology" (34), a própria noção de media (com base nas tradicionais distinções entre materiais e condições de perceção) está, pela sua inércia, em crise. Então, propõe um conjunto de linhas definidoras de uma estética "pós-media" que encara a cultura como software aplicável tanto ao panorama atual quanto ao do passado.

Há neste argumento mais semelhanças com Hayles do que parece, pois Manovich apela para a especificidade do computador, elegendo-o como a tecnologia através da qual as outras devem ser reconcetualizadas; mas fá-lo com uma noção teleológica do progresso e um determinismo tecnológico que são irrecebíveis. Além disso, mesmo reconhecendo uma continuidade entre formas, enfatiza sempre os movimentos de rutura, e ainda que admita que o passado é sempre "relido" em função da nossa visão do presente, parece esquecer (ou desvalorizar) que, para que um medium tenha propriedades intrínsecas, tem de ter como base uma tradição e uma continuidade que as estabelecem - e é aqui que o seu ensaio se distancia do de Hayles.

Fará (ainda) sentido este modelo "ciberestruturalista"? Kinder reconhece, na sua introdução, que tal visão "frequently (...) privileges formalism while ignoring the ideological implications of structural choices; it treats narrative as a rigid formal structure (...) minimizing its cognitive, affective and social functions" (4); por isso, o facto de "If-then-else: Memory and the path not taken" de Edward Branigan ter sido colocado a seguir a estes dois ensaios é sintomático para observar as fricções pretendidas por esta recolha. Fazendo jus ao mote "productive precursors", o texto examina cinco metáforas distintas (o bloco de cera de Platão, o bloco de notas místico de Freud, a cera impermeável de Descartes, o aviário de Platão e a linguística de Wittgenstein) para compreender como os modelos cognitivos do passado podem enriquecer o entendimento dos novos media. Deste modo, Branigan consegue repensar a especificidade dos media através de uma interatividade entre o pensamento presente e a memória de pensamentos do passado - mesmo quando se tornam "paths not taken". Sem entrar em determinismos tecnológicos, o ensaio pretende compreender como "these responses, collectively, become part of the historical memory that will shape the next version of a medium" (68) - o que é, de certo modo, também o objetivo do ensaio de Hayles.

O modelo "ciberestruturalista" vai sendo posto em causa - ou antes, submetido a friç̧ões - por diversas vezes ao longo da parte I, como por exemplo em "Navigating the oceans of streams of story", de Grahame Weinbren, no qual, citando Timothy Binkley, o autor argumenta que o computador não é um medium, por não ter caraterísticas inerentes que possam ser exploradas e expostas através de um gesto modernista, mas sim um camaleão, uma ferramenta universal cujas qualidades podem ser (re)definidas em cada utilização (143); e a superação do mesmo é finalmente confirmada em "Is this not a screen? Notes on the mobile phone and cinema" de Caroline Bassett, que encerra esta primeira parte, examinando a possibilidade da criação de formas fílmicas em telefones móveis. Entendendo que uma posição ontoló- 
gica irá fixar uma tecnologia em constante mutação numa conceção formalista, a autora debruça-se sobre o binómio representação-ação para expor argumentos acerca do caráter intimista e (sob o risco de cometer uma redundância) móvel deste medium; mas apesar da proliferação destes dispositivos, que é um efeito natural da "centrality of the visual within its economy" (157) e que os filia num arquétipo multimodal de práticas sociais que podem mediar a realidade, conclui que "mobile cinema never will be invented" (idem).

Esta progressão revela, então, que a recolha pretende não apenas decompor, mas também libertar-se de uma visão puramente formalista dos novos media, estando consciente de que, para o conseguir, não é suficiente inquirir a sua especificidade e os seus precursores - é ainda necessário, como o ensaio de Bassett demonstra de forma clara, discutir as suas possibilidades. E é nesse seguimento que McPherson, na introdução à parte II, alega que o estudo das relações entre raça, identidade, política e ecologia digital permitem, de igual modo, transpor as abordagens formalistas, trazendo a lume epistemologias que já invadiram outros campos do saber.

Esta retórica admite, todavia, determinados riscos epistemológicos, desde logo patentes em "Thinking digitally, acting locally: Interactive narrative, neighborhood soil, and La Cosecha Nuestra Community”, de John T. Caldwell: sendo um trabalho de campo realizado junto de uma comunidade rural hispânica que se autorretratou por recurso ao filme digital, este ensaio está demasiadamente instaurado na metodologia dos cultural studies para indagar as modalidades transmedia de uma forma produtiva. Mas a questão principal reside na própria amplitude do campo das "Politics of...", que viabiliza o tratamento do mais variado número de temáticas - até mesmo a especificidade dos media e os seus precursores... E talvez seja por estes dois motivos que os ensaios mais estimulantes da parte II sejam os que se reportam aos temas da anterior. É o caso de "Transnational/ National digital imaginaries", de John Hess e Patricia R. Zimmerman, que observa determinadas culturas "marginalizadas" que fazem um uso "alternativo" da tecnologia digital. Através da análise de filmes documentais que criam um vínculo entre "estética" e "política" ao retratar a memória e o corpo, particularmente na sua dimensão racial, o ensaio explora, de forma competente, a forma como as dinâmicas de rutura e de continuidade entre as modalidades cinemáticas analógicas e as digitais se relacionam com a questão do "digital divide" (ou seja, a problemática das esferas sociais e/ou geográficas que estão "à parte" da "revolução digital"), para concluir que "the analog forms of racialized body are always embedded within the digital, just not always visualized" (191). Merece ainda destaque o texto de Mark B. N. Hansen, "Video installation art as uncanny shock, or how Bruce Nauman's corridors expand sensory life", que, abordando o "choque" que as imagens deste cineasta exercem no espetador, conclui que não é a imagem vídeo, em si, que provoca o choque, mas sim a forma como esta apresenta corpos que, marcados pela sua História, cultura, raça e ideologia, surgem deformados e desprovidos dos clichés da representa- 
ção. Contudo, é por apresentar uma bem fundamentada arqueologia da teoria fílmica (por via de uma análise da materialidade fílmica e videográfica suportada nas teorias de Walter Benjamin ou Gilles Deleuze) que o ensaio se torna convincente, e por mostrar (como Hayles, já agora) que a materialidade é algo para além da fisicalidade, nunca estando garantida pelo seu dispositivo e tendo antes de emergir através da hermenêutica e do debate.

No cômputo geral, Transmedia Frictions ambiciona, claramente, suplantar o discurso das diferenças funcionais daquilo que é "novo" nos novos media, propondo hipóteses alternativas para os estudos digitais no campo das humanidades. O movimento realizado por estes ensaios é revelador: decompor ontologicamente o digital de forma a legitimá-lo, para depois demonstrar que se trata de uma ecologia compatível com as visões dos estudos culturais, póscoloniais e da identidade. Por este gesto de acompanhamento do movimento mais alargado da Teoria, e por propor vias de debate alternativas, merece um lugar de destaque no campo de estudos das humanidades e dos media. Já a forma algo viciada como parece querer persuadir o leitor a convencer-se dessa necessidade, aliada ao facto de nem sempre ser possível ver uma verdadeira fricção entre os dois "grandes temas" do livro, fica como aspeto menos positivo da recolha. "Sim, sempre a política, não lhe podemos fugir", alertanos uma personagem do romance The Names, de Don DeLillo; consciente dessa inevitabilidade, Transmedia Frictions deu o mote - resta-nos esperar, agora, que outros se sirvam deste testemunho para produzir fricções mais produtivas.

(C) 2016 Bruno Fontes.

Licensed under the Creative Commons Attribution-Noncommercial-

No Derivative Works 4.0 International (CC BY-NC-ND 4.0). 